\title{
Editorial: Porous Nanomaterials for Superior Energy Storage Devices
}

\author{
Jinliang $L^{1 *}{ }^{1 *}$ Wei Qin ${ }^{2}$ and Muhammad Sufyan Javed ${ }^{1,3}$ \\ ${ }^{1}$ Siyuan Laboratory, Guangdong Provincial Engineering Technology Research Center of Vacuum Coating Technologies and New \\ Energy Materials, Department of Physics, Jinan University, Guangzhou, China, ${ }^{2}$ School of Materials Science and Engineering, \\ Changsha University of Science and Technology, Changsha, China, ${ }^{3}$ Department of Physics, COMSATS University Islamabad \\ Lahore Campus, Lahore, Pakistan
}

Keywords: porous nanomaterials, energy conversion, energy storage, solar cells, photocatalysis

\section{OPEN ACCESS}

Edited and reviewed by: Jintao Zhang,

Shandong University, China

${ }^{*}$ Correspondence:

Jinliang $L i$

lijinliang@email.jnu.edu.cn

Specialty section: This article was submitted to

Energy Materials,

a section of the journal

Frontiers in Materials

Received: 27 April 2021

Accepted: 30 April 2021

Published: 17 May 2021

Citation:

Li J, Qin W and Javed MS (2021) Editorial: Porous Nanomaterials for

Superior Energy Storage Devices.

Front. Mater. 8:700950.

doi: $10.3389 /$ fmats.2021.700950

\section{Editorial on the Research Topic}

\section{Porous Nanomaterials for Superior Energy Storage Devices}

The energy issue becomes one of the three major problems facing the society at present. With the rapid growth of global energy demand, the existing fossil fuel-based infrastructure is no longer able to meet the current needs of society. Therefore, alternative technologies should be developed and mobilized, especially those in the development of efficient energy conversion and storage technologies. While advanced energy conversion-storage concepts and renewable energy systems have been the focus of considerable attention in the past decade.

This special issue-mainly focuses on the porous nanomaterials for superior energy conversion and storage devices-consists of three papers spanning topics detailing the porous nanofiber as counter electrode for dye-sensitized solar cells, microwave-assisted synthesis of porous composite for energy conversion and heteroatom decorated mesoporous materials for photocatalysis. Sun et al. synthesized $\mathrm{MoS}_{2}$-carbon nanofiber composites with electrospinning technique as counter electrode for dye-sensitized solar cells, achieving a maximum efficiency of 5.7\%. Yi et al. utilized microwaveassisted method to obtain porous $\mathrm{MoS}_{2}$-graphene composite to realize a high conversion efficiency in solar cells, demonstrating that the improvement of conversion efficiency is due to the high electrical conductivity and catalytic ability of composite. Ni et al. developed nitrogen and copper co-doped carbon dots/mesoporous $\mathrm{WO}_{3}$ nanocomposite to realize a broad-spectrum response, which facilitate the photocatalytic reaction under UV-vis-NIR light irradiation. 


\section{AUTHOR CONTRIBUTIONS}

All authors listed have made a substantial, direct, and intellectual contribution to the work and approved it for publication.

\section{ACKNOWLEDGMENTS}

We would like to express our sincerest gratitude to all the authors and reviewers who contribute to this special issue. We hope that more readers will find this special edition accurate, and pragmatic guide to applications in the synthesis of porous nanomaterials for energy conversion and storage field.

Conflict of Interest: The authors declare that the research was conducted in the absence of any commercial or financial relationships that could be construed as a potential conflict of interest.

Copyright $\odot 2021 \mathrm{Li}$, Qin and Javed. This is an open-access article distributed under the terms of the Creative Commons Attribution License (CC BY). The use, distribution or reproduction in other forums is permitted, provided the original author(s) and the copyright owner(s) are credited and that the original publication in this journal is cited, in accordance with accepted academic practice. No use, distribution or reproduction is permitted which does not comply with these terms. 